\title{
Wat kunnen België en Nederland van elkaar leren over zakelijke bemiddeling?
}

\author{
Theo De Beir \& Willem Meuwissen
}

Deze bijdrage geeft een Belgische kijk op het Nederlandse ZAM/ACB-onderzoek naar kansen en belemmeringen voor zakelijke mediation onder advocaten, bedrijven en rechters. ${ }^{1}$ Dit onderzoek werd in Nederland uitgevoerd door de Vereniging Zakelijke Mediation (ZAM), de Stichting ADR Centrum voor het Bedrijfsleven (ACB) in samenwerking met het Montaigne Centrum voor Rechtspraak en Rechtspleging van de Universiteit Utrecht.

In België promoten gelijkaardige instellingen zoals bMediation, Cepani en Bemiddeling $\mathrm{vZW}^{2}$ zakelijke bemiddeling en bieden zij daarnaast bemiddelingsdiensten aan het zakelijke publiek en stellen lijsten van gespecialiseerde bemiddelaars ter beschikking.

\section{Groeiende belangstelling}

Ook in België is sinds de jaren negentig van de vorige eeuw de aandacht voor bemiddeling aanzienlijk toegenomen. ${ }^{3}$ De traditionele 'één tegen allen, allen tegen één'-strijd bij zakelijke conflicten wordt steeds minder gewaardeerd. Bij advocaten, bedrijfsjuristen en magistraten en ook bij het zakelijke cliënteel, doet zich een mentaliteitswijziging voor, gericht op minnelijke regeling, samenwerking en een positieve uitkomst voor alle betrokken partijen. Andere factoren dan het juridische gelijk, zoals het vervullen van belangen, het vinden van zakelijk relevante oplossingen en het behouden van de zakelijke relatie treden steeds meer op de voorgrond.

Deze change of mind, en soms wel of heart, doet zich in de eerste plaats voor in de juridische praktijk. bMediation geeft sinds 1999 aan rechtspractici opleiding in

1 M. Thomas, M. de Kort-de Wolde, E. Schutte \& M. Schonewille, ZAM/ACB Onderzoek naar kansen en belemmeringen voor zakelijke mediation, Utrecht: Montaigne Centrum voor Rechtsspraak en Rechtspleging 2018, te raadplegen op: www.uu.nl/nieuws/onderzoeksrapport-naar-zakelijkemediation-in-nederland.

2 Zie www.bmediation.eu; www.cepani.be en www.bemiddelingvzw.be.

3 Zie T. De Beir, De kracht van bemiddeling en de rol van de advocaat en de magistraat, in: J. Flo, L. Janssens \& Vlaams Pleitgenootschap (red.), Smaakmakers in het procesrecht. Over buitengerechtelijke recepten, vergeten vorderingen en exotische incidenten, Antwerpen: Intersentia 2016, p. 155-182. 
zakelijke bemiddeling. De Belgische rechtsleer heeft aan die professionele evolutie een juridisch theoretische onderbouw verschaft. ${ }^{4}$

De wind van bemiddeling waait eveneens door de juridische opleidingen aan de Belgische universiteiten. Rechtenstudenten worden opgeleid met theoretische en praktische kennis over de essentie van bemiddeling. Zij leren dat bemiddeling een efficiënte en adequate manier van geschillenoplossing is. De universiteiten te Leuven, Gent en Antwerpen onderwijzen in de eerste of tweede Master Rechten Onderhandelen en Bemiddelen als opgelegd studievak.

Als een van de eerste landen in de Europese Unie heeft België in 2005 bemiddeling wettelijk gereglementeerd en als middel van conflictoplossing opgenomen in het Belgisch Gerechtelijk Wetboek. ${ }^{5}$ De Belgische wetgever heeft het belang dat hij hecht aan bemiddeling verder onderlijnd door de Wet van 18 juni 2018, ${ }^{6}$ die niet alleen de Bemiddelingswet verfijnt, maar ook aan collaboratieve onderhandelingen een wettelijke basis verschaft en deze opneemt in het Gerechtelijk Wetboek. ${ }^{7}$

In België waakt de door de Bemiddelingswet gecreëerde Federale Bemiddelingscommissie over de kwaliteit van de bemiddelingsdiensten. Zij borgt de kwaliteit van de opleidingsinstituten en de opleidingen, zij kent de wettelijk beschermde titel van Erkende Bemiddelaar toe aan professionelen die aantonen de juiste opleiding te hebben gevolgd en biedt de nodige professionele waarborgen voor het uitoefenen van het bemiddelaarsvak.

De Bemiddelingswet geeft een wettelijke verankering aan belangrijke principes van bemiddeling, zoals de vertrouwelijkheid van de bemiddeling en aan het beroepsgeheim van de bemiddelaar.

4 J. Cruyplants, M. Gonda \& M. Wagemans, Droit et Pratique de la Médiation, Brussel: Bruylant 2008. S. De Bauw \& B. Gayse, Bemiddeling en Rechtspraak hand in hand. Wegwijs voor de Rechter, Brugge: Die Keure 2009. C. Smets-Gary \& M. Becker, Médiation et Techniques de Négociation Intégrative, Brussel: Larcier 2012. W. Meuwissen, Bemiddeling, De Praktische Gids, Mechelen: Kluwer 2016, 2de herziene druk 2018. T. De Beir, De Nieuwe Bemiddelingswet, in: S. Rutten \& L. Demeyere, Conflictafhandeling buiten de Rechtbank, Antwerpen: Intersentia 2019, p. 224.

5 Wet van 21 februari 2005 tot wijziging van het Gerechtelijk Wetboek in verband met de bemiddeling (BS 22 maart 2005). De wet is in voege sinds 30 september 2005. De bepalingen betreffende de Federale Bemiddelingscommissie zijn in voege sinds 22 maart 2005. De wet werd twee maal gewijzigd. De wet van 23 april 2014 voegde een paragraaf 8 toe aan art. 1727 Ger. W. dat voor de toepassing van de Bemiddelingswet een gelijkstelling doorvoert tussen kandidaat-notarissen en notarissen. De wet van 19 oktober 2015 in voege vanaf 1 november 2015 brengt de termijn van aanstelling van een gerechtelijke bemiddelaar van drie naar zes maanden.

6 Wet van 18 juni 2018, waarvan titel 9 handelt over diverse wijzigingen van het Gerechtelijk Wetboek met het oog op de bevordering van alternatieve vormen van geschillenoplossing (BS 2 juli 2018). Voorbereidende werken. Wetsontwerp 54K2919 van 5 februari 2018, p.7859. Verslag Tweede Lezing Brotcorne van 31 mei 2018, p. 8668 aangenomen in plenaire zitting van de Kamer op 7 juni 2018. De wet is in voege getreden op 1 januari 2019, behalve de wijzigingen aan art. 1728 tot 1735 die in werking traden op 12 juli 2018. De regeling met betrekking tot de collaboratieve onderhandelingen trad in werking op 1 januari 2019.

7 W. Meuwissen, Nieuw in België: Collaboratieve Onderhandelingen wettelijk geregeld, TMD 2018 (22) 4, p. 66. W. Meuwissen, Collaboratieve Onderhandelingen, in: S. Rutten \& L. Demeyere (red.) Conflictafhandeling buiten de rechtbank, Antwerpen: Intersentia 2019, p. 161-240. 


\section{Belgische bemiddeling in het kort}

België kent een omvattende wettelijke regeling omtrent bemiddeling, zowel buitengerechtelijk als gerechtelijk. Het wettelijk regelen van bemiddeling stimuleert het gebruik ervan, promoot de bekendheid van ADR en komt de juridische zekerheid ten goede. ${ }^{8}$

Bemiddeling wordt wettelijk geregeld in de artikelen 1723/1-1737 van het Belgische Gerechtelijk Wetboek. De wet van 18 juni 2018 definieert bemiddeling als 'een vertrouwelijk en gestructureerd proces van vrijwillig overleg tussen conflicterende partijen met de medewerking van een onafhankelijke, neutrale en onpartijdige derde die de communicatie vergemakkelijkt en poogt de partijen ertoe te brengen zelf een oplossing uit te werken'. ${ }^{9}$

Alle geschillen van vermogensrechtelijke aard, alsmede de geschillen van niet-vermogensrechtelijke aard die vatbaar zijn voor dading, kunnen het voorwerp vormen van een bemiddeling, ook als een publiekrechtelijke rechtspersoon in het conflict betrokken is. Ook veel familierechtelijke conflicten kunnen het voorwerp van bemiddeling vormen. De Bemiddelingswet bepaalt de voorwaarden, waaraan een erkende bemiddelaar dient te voldoen en beschermt de titel, ook strafrechtelijk. De erkende bemiddelaar geniet het strafrechtelijk beschermde monopolie van de niet-zakelijke bemiddelingen. Om internationaal opererende bemiddelaars in zakelijke conflicten toe te laten en ongestraft actief te laten zijn, heeft de Belgische wetgever naar verluidt de zakelijke bemiddelaars ontslagen van de strafrechtelijke verplichting erkend te zijn. De wet bepaalt de oprichting, de structuur en de werking van de Federale Bemiddelingscommissie. Het bemiddelingsbeding in contracten en de gelding daarvan in geval van een procedure wordt eveneens geregeld. De vertrouwelijkheid van de besprekingen tussen de deelnemers en de tegenstelbaarheid van de vertrouwelijkheid aan de rechter en de arbiter zijn wettelijk vastgelegd, alsmede het beroepsgeheim van de bemiddelaar en van de experten die in het kader van de bemiddeling geraadpleegd worden. De wet bepaalt dat bemiddeling vrijwillig is, namelijk dat iedere deelnemer het recht heeft de bemiddeling op ieder ogenblik te beëindigen zonder dat dit hem tot nadeel kan strekken.

De Bemiddelingswet maakt een onderscheid tussen gerechtelijke bemiddeling ${ }^{10}$ en buitengerechtelijke bemiddeling. ${ }^{11}$ Gerechtelijke bemiddeling vindt plaats in het kader van een hangend geding, waarbij de rechter het akkoord van de partijen met het uitvoeren van een bemiddeling opneemt in een vonnis. Sinds het in werking treden van de nieuwe Bemiddelingswet in 2018 kan de Belgische rechter zelfs een bemiddeling dwingend opleggen aan de partijen. Concreet betekent dit

8 Over de definitie van bemiddeling, zie T. Wijnant, Verplichte doorwijzing naar bemiddeling: we can lead a horse to water, but can we make it drink?, TMD 2018 (22) 2, p. 65-66.

9 Art. 1723/1 Ger.W.

10 Art. 1734 e.v. Ger.W.

11 Art. 1730 e.v. Ger.W.; tot voor de wet van 18 juni 2018 noemde de wetgever dit 'vrijwillige bemiddeling', namelijk een bemiddeling door de partijen samen overeengekomen en georganiseerd. De wet van 18 juni 2018 beoogt met deze semantische wijziging het onderscheid tussen de twee bemiddelingsvormen duidelijker maken. Zie Parl. St. Kamer 2017-18, nr. 54-2919/001, 55. 
dat de partijen een akkoord dienen te treffen over de persoon van de bemiddelaar, bij gebrek waaraan de rechter die zelf aanstelt, dat zij een bemiddelingsprotocol dienen te ondertekenen, het voorschot van de bemiddelaar dienen te betalen, aan de bemiddelaar alle nodige informatie dienen te bezorgen en aanwezig dienen te zijn op de eerste bemiddelingssessie. De rechter kan dit opleggen op verzoek van een partij of ambtshalve, behalve als alle partijen zich tegen een bemiddeling verzetten. Buitengerechtelijke bemiddeling behelst alle andere bemiddelingen. Deze laatste categorie is numeriek ongeveer vijfmaal groter dan de gerechtelijke bemiddeling. ${ }^{12}$

Bij beide soorten bemiddeling dienen de partijen en de bemiddelaar een bemiddelingsprotocol te ondertekenen. Leidt de bemiddeling tot een minnelijke regeling, dan wordt dit opgenomen in een bemiddelingsakkoord dat de hoedanigheid van een vaststellingsovereenkomst of een dading heeft. De partijen samen kunnen, maar ook één van hen apart kan van het bemiddelingsakkoord een uitvoerbare titel bekomen door een homologatieprocedure bij de bevoegde rechter, die op eenzijdig verzoekschrift kan verlopen in geval van buitengerechtelijke bemiddeling en die in het kader van een gerechtelijke bemiddeling aan de rechter bij conclusie - ook eenzijdig - kan worden gevraagd.

\section{Zakelijke bemiddeling, in België}

Volgens het ZAM/ACB-rapport bestaat er geen overeenstemming over de precieze inhoud van het begrip 'zakelijke mediation'. Het rapport beschrijft dit als: 'Mediation in geschillen tussen bedrijven en bedrijfsonderdelen en in geschillen tussen andere professionele partijen, waaronder ook aandeelhoudersgeschillen en contractuele conflicten.' Uit het rapport blijkt ook dat het merendeel van de bevraagde personen ook arbeidsconflicten als onderdeel van 'zakelijke mediation' beschouwt.

Tot voor de inwerkingtreding van de wet van 18 juni 2018 maakte de Belgische wetgever een onderscheid tussen bemiddeling in familiezaken, bemiddeling in sociale zaken en bemiddeling in burgerlijke en handelszaken zoals voorzien in het toenmalige artikel 1726, $\S 1,1^{\circ}$ Ger.W. ${ }^{13}$ Ook maakte de wetgever een onderscheid in bemiddelaars, die een specifieke opleiding voor ieder van de drie soorten bemiddeling dienden te volgen om in de overeenkomstige categorie te kunnen worden erkend.

De wet van 18 juni 2018 schrapte het onderscheid, omdat de wetgever had ingezien dat het voor de bemiddelingspraktijk niet relevant was. Veel bemiddelingen combineren aspecten van familiale en zakelijke aard of van zakelijke en sociale aard. De Belgische wetgever beschouwt een erkende bemiddelaar nu als een generalist (minstens honderd uren opleiding, vroeger zestig uren) die bekwaam is om te bemiddelen in alle soorten geschillen. Anderzijds heeft de wetgever bepaald dat

12 bMediation, Bemiddelingsbarometer 2016, www.bmediation.eu/images/stories/publications/ bemiddelingsbarometer\%202016\%20nl\%20final.pdf, p. 6.

13 Dit waren de drie door de Bemiddelingswet geregelde vormen. Er bestaan nog andere 'soorten' bemiddeling, zoals strafbemiddeling of bemiddeling in vergunningszaken, maar die worden door andere wettelijke bepalingen beheerst. 
een erkende bemiddelaar naast de algemene opleiding ook minstens een specifieke opleiding dient te volgen, waarvoor de Federale Bemiddelingscommissie vijf specialisatiemodules heeft uitgewerkt, namelijk bemiddeling in familiezaken, in burgerlijke zaken, in ondernemingszaken, in arbeidsrelaties en sociale zekerheid en in bemiddeling met overheidsinstanties. De wetgever ziet de bemiddelaar dus als een 'gespecialiseerde generalist'.

Ook dient elke erkende bemiddelaar per twee jaar beroepsactiviteit minstens achttien uren door de Federale Bemiddelingscommissie erkende bijscholing te volgen.

\section{De Bemiddelingsbarometer}

In België wordt de bemiddelingsactiviteit periodiek gemonitord aan de hand van de Bemiddelingsbarometer. Dit onderzoek is een initiatief van bMediation in samenwerking met de Federale Bemiddelingscommissie en de Universiteit van Gent. ${ }^{14}$

Voor het opstellen van de Bemiddelingsbarometer van 2018 contacteerde bMediation in totaal 1.800 bemiddelaars met verzoek een online enquête in te vullen. Daarop hebben 505 bemiddelaars gereageerd en daarvan werden 474 antwoorden gevalideerd. 97\% van die bemiddelaars zijn erkende bemiddelaars. Het aantal erkende bemiddelaars in België zit in de lift. ${ }^{15}$ Het merendeel van de Belgische erkende bemiddelaars is eveneens advocaat.

Bij buitengerechtelijke bemiddelingen bedraagt de successcore gemiddeld $75 \%$. Bij gerechtelijke bemiddelingen ligt de succesgraad op 60 tot $70 \%$. Wellicht valt dit verschil in successcore te verklaren door de hogere escalatiegraad van de geschillen die al voor de rechtbank hangend zijn en door het verschijnsel dat partijen niet durven weigeren als de rechter hun een bemiddeling voorstelt, alhoewel ze daar niets voor voelen. Bemiddeling in commercieel gerelateerde dossiers vindt doorgaans plaats bij geschillen betreffende vastgoed, onenigheden tussen vennoten en algemene geschillen in onder andere handel en distributie. ${ }^{16}$

Een bemiddelaar heeft gemiddeld vier sessies nodig, die in totaal ongeveer twintig uren aan bemiddeling in beslag nemen en deze strekken zich uit over een gemiddeld 45 dagen durend bemiddelingstraject. Een bemiddeling kost gemiddeld $€ 3.000$, wat gunstig is in vergelijking met de kosten van een juridische procedure. De Bemiddelingsbarometer van 2018 toont aan wat het professionele cliënteel aantrekt in bemiddeling: een lagere kostprijs, kortere duur, hoge slaagkans en de mogelijkheid om tot een oplossing te komen die door alle partijen gedragen wordt.

Het ZAM/ACB-rapport vermeldt gelijkaardige redenen waarom advocaten, rechters en bedrijven overwegen om over te gaan tot bemiddeling. Voor advocaten is

14 Een samenvatting daarvan is terug te vinden op de webstek van bMediation: www.bmediation. eu.

15 Zie hiervoor T. Wijnant, Bevraging van de Belgische advocatuur over bemiddeling: eerste resultaten, TMD 2018 (22) 1, p. 22-39.

16 Dit blijkt ook uit de Bemiddelingsbarometer van 2016. 
dit voornamelijk de snelheid van het bemiddelingstraject en het vermijden van de onzekerheid van een rechtszaak. Bedrijven halen als reden voor bemiddeling vooral snelheid aan en de relatie met de wederpartij. Bemiddeling kan er immers voor zorgen dat de relatie tussen partijen hersteld en/of verbeterd kan worden of kan helpen om die op een zorgvuldige en correcte wijze te beëindigen. Uit de bevraging van de rechters blijkt dat de relatie tussen de partijen een belangrijke reden is voor bemiddeling, wat onderlijnt dat er in een rechtsgeding naast juridische ook emotionele factoren aanwezig zijn.

Blijkens het rapport menen Nederlandse advocaten dat de belangrijkste redenen waarom advocaten niet willen overgaan tot bemiddeling, gelegen zijn in de weerstand bij de cliënt tegen het bemiddelingsidee en de wens meer druk uit te oefenen via een gerechtsprocedure. Ook bedrijven vinden de druk die met een juridische procedure kan worden uitgeoefend een belangrijke reden, alsook problemen om een goede bemiddelaar te vinden of het omtrent diens identiteit eens te worden met de wederpartij. Advocaten en rechters menen daarentegen wel beroep te kunnen doen op goede bemiddelaars. Ook in de ogen van rechters is de weerstand bij de partijen een grote belemmering voor bemiddeling. Een deel van de bevraagde rechters vindt dat er niet tot bemiddeling moet worden overgegaan, omdat het vellen van een uitspraak hun professionele opdracht is en het precies daarom is dat de partijen zich tot de rechter hebben gewend.

In complexe zaken of zaken met veel partijen, kan worden overwogen meer dan een bemiddelaar aan te stellen. Nochtans heeft $84 \%$ van de responderende bemiddelaars geantwoord niet open te staan voor co-bemiddeling. Eventueel heeft dit te maken met het oplopen van de kosten van de bemiddeling en de toenemende complexiteit van de communicatie waarmee co-bemiddeling gepaard gaat.

\section{Zijn de resultaten van het $\mathrm{ZAM} / \mathrm{ACB}$-rapport en de Belgische Bemiddelingsbarometer gelijklopend?}

In België zowel als in Nederland blijkt de voorkeur voor de traditionele juridische aanpak vooral voort te vloeien uit onwil en onwetendheid bij partijen en hun adviseurs.

Nederlandse advocaten zijn meer dan hun Belgische collega's met zakelijke bemiddeling in contact gekomen, maar in België gaat de adviespraktijk in bemiddeling in stijgende lijn. Het blijkt soms moeilijk om de juridische en rechtbankgerichte bril af te zetten. Ook magistraten en bedrijven vertonen steeds grotere belangstelling voor bemiddeling, wat resulteert in een toename van het aantal bemiddelingen.

De Nederlandse advocaten blijken het belangrijk te vinden dat bemiddelaars aangesloten zijn bij een bemiddelaarsverband of een internationaal verband en dat zij onderdeel uitmaken van een kantoor of samenwerkingsverband. Tevens hechten Nederlandse advocaten belang aan roots en opgedane ervaring in het bedrijfsleven. Ook waarderen zij zeer de juridische kennis van de bemiddelaar. Het rapport toont aan dat het merendeel van de bedrijven deze visie deelt. 
In België wordt kwaliteit bij de bemiddelaars nagestreefd door het opleggen van erkende opleidingen en erkende permanente vorming. De Belgische wetgever heeft de opleidingsvereisten voor de erkende bemiddelaars ter gelegenheid van de recente wetswijziging verstrengd.

De theoretische opleiding omvat verplicht een juridische component en het praktische deel omvat de bemiddelingsvaardigheden en de kennis van het bemiddelingstraject. De Federale Bemiddelingscommissie legt een verplichte evaluatieproef op. De erkende bemiddelaar dient de nodige waarborgen te bieden inzake onafhankelijkheid, neutraliteit en onpartijdigheid. Het respecteren van de deontologische code, opgesteld door de Belgische Federale Bemiddelingscommissie, draagt eveneens bij tot de kwaliteitsborging.

\section{Zijn er verschillen in bemiddelingstechniek tussen België en Nederland?}

Tussen het Noorden en het Zuiden bestaan wel verschillende visies op de aan te wenden bemiddelingstechnieken.

\section{Individuele intakegesprekken}

Uit het rapport blijkt dat het merendeel van de Nederlandse bevraagden individuele intakegesprekken apprecieert. Een individueel intakegesprek houdt in dat de bemiddelaar voorafgaandelijk met elke partij apart samenzit om diens standpunten te beluisteren.

In België lopen de visies uiteen. Enerzijds zijn er bemiddelaars die er de voorkeur aan geven de bemiddeling met een 'schone lei' aan te vatten, dus zonder voorafgaande kennis omtrent het geschil om een volledige neutraliteit en onpartijdigheid te garanderen. Andere bemiddelaars verkiezen om voorbereid aan de slag te gaan en ontmoeten de partijen en hun raadslieden in een voorafgaand apart gesprek. Deze bemiddelaars vragen gewoonlijk ook aan de partijen een korte samenvatting van het conflict op te stellen en hun dossiers over te maken. Het betreft gewoonlijk bemiddelingen over ingewikkelde kwesties en grote belangen, zoals bemiddelingen over de uitvoering van technisch en juridisch ingewikkelde contracten waarbij de partijen een aan de sector eigen jargon hanteren en in hun communicatie verwijzen naar complexe contractuele relaties. Daar bestaat de noodzaak dat de bemiddelaar zich eerst in het dossier inleest om de partijen te kunnen begrijpen.

\section{Sturende kracht}

Uit het rapport blijkt dat Nederlandse bemiddelaars minder geneigd zijn om te sturen op de inhoud van het akkoord, maar dat de cliënten en de advocaten een sturende bemiddelaar wensen. Nederlandse advocaten en bedrijven blijken volgens het rapport voorstander te zijn van een bemiddelaar die zich uitlaat over de kansen en risico's om de partijen in de richting van een regeling te sturen. Dit gaat in tegen de visie van de leidende Nederlandse bemiddelaarsorganisatie die faciliterende bemiddeling als enige bemiddelingstechniek vooropstelt. 
In België huldigen meerdere erkende bemiddelaars het ADR-axioma Fit the Forum to the Fuss, wat erop neerkomt dat een erkende bemiddelaar de technieken moet toepassen die nodig zijn om het cliënteel naar een minnelijke regeling brengen. Alle bemiddelaars zijn in mindere of meerdere mate taakinhoudelijk en sociaalemotioneel actief. Hun interventies zijn naargelang de noodwendigheden van de bemiddeling faciliterend, evaluerend, transformatief of narratief. Iedere bemiddeling draagt in mindere of meerdere mate in zich de nood aan elk van deze interventiestijlen. De bemiddelaar past op grond van zijn vakmanschap en ervaring de verschillende interventiestijlen op het juiste ogenblik van de bemiddeling in de juiste mix toe. ${ }^{17}$ In de Verenigde Staten van Amerika wordt deze benadering ook wel aangeduid als eclectic mediation.

De Belgische wetgever heeft in 2005 geen aanwijzing verschaft over de bemiddelingsstijl die hij van de bemiddelaar verwacht. In 2018 is daarin verandering gekomen. Artikel 1726 Ger.W. bepaalt nu dat de bemiddelaar niet alleen onpartijdig en onafhankelijk, maar ook neutraal dient te zijn. Ook de Europese Gedragscode voor Bemiddelaars vermeldt de neutraliteit van de bemiddelaar. De neutrale bemiddelaar oefent geen invloed uit op de inhoud van het bemiddelingsakkoord. Hij eerbiedigt maximaal de wilsautonomie van de partijen. De neutrale bemiddelaar doet bijgevolg aan faciliterende taakinhoudelijke bemiddeling. Er dient te worden afgewacht hoe de nieuwe deontologische regels die de Belgische Federale Bemiddelingscommissie zal uitvaardigen naar aanleiding van de inwerkingtreding van de nieuwe Bemiddelingswet met het begrip neutraliteit zullen omgaan.

Redelijkerwijs behoort het echter niet de wetgever toe te bepalen welke bemiddelingstechnieken de professionele, erkende bemiddelaar dient toe te passen. Dit is een zaak van de bemiddelingsprofessioneel die de gehanteerde technieken zelf bepaalt en zijn interventies dient te inspireren op wat internationaal als goede bemiddelingspraktijk wordt erkend.

In de Belgische bemiddelingspraktijk nemen bepaalde bemiddelaars vaker een sturende rol op, omdat de omstandigheden daartoe nopen en de blokkering anders volledig blijkt te zijn. ${ }^{18} \mathrm{Zij}$ vinden de uitsluitend faciliterende rol van bemiddelaars te beperkend om de partijen toe te laten een win-winsituatie te creëren. ${ }^{19}$ Ook in de Verenigde Staten van Amerika gaan bemiddelaars verder dan puur faciliterende interventies. Zij spreken zich zelfs uit over de grond, al dan niet juridisch, van het geschil zelf. ${ }^{20}$ Soms is het noodzakelijk om tijdens de bemiddeling de juridische aspecten van het conflict te behandelen. Patrick Van Leynseele poneerde reeds in 2014 dat het tot een goede bemiddelingspraktijk behoort dat een bemiddelaar in de loop van het bemiddelingstraject zijn opinie geeft, namelijk als redenen van efficiëntie dit vereisen of als de partijen daar

17 W. Meuwissen, Bemiddeling: de Praktische Gids, tweede herziene druk, Mechelen: Kluwer 2018, p. 110.

18 P. Van Leynseele, Médiation 'facilitative' ou 'évaluative': devons-nous changer de point de vue?, JT 2014, p. 609-611.

19 Ibid., p. 609-610.

20 Ibid., p. 610. 
expliciet naar vragen. Indien een bemiddelaar verder wenst te gaan dan puur faciliteren, dan dient hij over de nodige vaardigheden te beschikken om dit op een gedegen en voor alle partijen aanvaardbare wijze te doen, zowel op het vlak van communicatie als naar juridisch inzicht. Ook dient de mogelijkheid tot het verrichten van dergelijke interventies reeds in het bemiddelingsprotocol te worden vermeld. ${ }^{21}$

In lijn met de Belgische wetgever kan worden gesteld dat de faciliterende bemiddelaar de regel is. Anderzijds kunnen de noodwendigheden van de bemiddelingspraktijk vergen dat de bemiddelaar sturende interventies verricht op de inhoud van het bemiddelingsakkoord. Dit houdt evenwel risico's in en dient dus goed gekaderd en voorbereid te zijn. De bemiddelaar dient dan ook kennis van zaken te hebben in de conflictmaterie.

\section{Mediation proposals}

Mediation proposals zijn voorstellen van akkoord die de bemiddelaar zelf op tafel legt als de onderhandeling tussen de partijen onvoldoende evolueert. Ook mediation proposals blijken volgens het rapport door Nederlandse advocaten en bedrijven positief onthaald te worden. Velen hebben er zelfs geen bezwaar tegen dat de bemiddelaar een bindend advies uitbrengt, in België een bindende derdenbeslissing genaamd.

In België behoort dit niet tot de bemiddelingspraktijk. Dit neigt naar hybride vormen van conflictoplossing zoals Med-Arb en Arb-Med. De hybride houding die de bemiddelaar/arbiter/bindende derdenbeslisser in de loop van de conflicthantering aanneemt, leidt redelijkerwijs tot het aannemen door de partijen van een strategische houding tegenover de bemiddelaar. De deelnemers modelleren ten overstaan van de bemiddelaar de communicatie over hun belangen en opties derwijze, dat zij van de bemiddelaar een voor hen gunstig voorstel verkrijgen. Ook kunnen de deelnemers de caucus of het apart gesprek aanwenden om in afwezigheid van de andere deelnemers de bemiddelaar voor zich in te nemen om deze in de richting van een bepaald voorstel te sturen. De andere deelnemer heeft hierop geen vat, want is geheel onwetend. De bemiddelingswetgeving is echter niet van dwingend recht, zodat de partijen deze modaliteit van hun bemiddeling in het bemiddelingsprotocol kunnen overeenkomen.

\section{Hoe denkt de Belgische advocaat over bemiddeling?}

In 2017 heeft Tom Wijnant (Universiteit van Gent) een empirisch onderzoek uitgevoerd naar de houding van de Belgische advocatuur ten opzichte van bemiddeling. ${ }^{22}$ Hieruit kwam een aantal interessante bevindingen naar voren.

Belgische advocaten staan in het algemeen positief ten opzichte van bemiddeling. Ze zien het niet als een zwaktebod, vinden bemiddeling een nuttig alternatief voor gerechtsprocedures en menen dat bemiddeling complementair kan zijn met

21 Ibid, p. 611.

22 T. Wijnant, Bevraging van de Belgische advocatuur over bemiddeling: eerste resultaten, TMD 2018 (22) 1, p. 22-39. 
de gebruikelijke rechtspraktijk. Van de respondenten gaf $71 \%$ aan vertrouwen te hebben in bemiddeling als een geschiloplossend alternatief en acht $90 \%$ dat de advocaat in het bemiddelingstraject een belangrijke rol speelt van begeleiding en ondersteuning van de cliënt. ${ }^{23}$

Uit het onderzoek bleek dat, ondanks de positieve houding van de advocatuur tegenover bemiddeling, een aantal factoren de groei van bemiddeling bemoeilijkt:

- Hardnekkige misverstanden: ${ }^{24}$ een groot aantal advocaten meent dat een bemiddelaar een bindende oplossing kan opleggen en dat het wettelijk mogelijk is dat bemiddeling door de rechter kan worden opgelegd. Ook bestaat het misverstand dat in het kader van een gerechtelijke bemiddeling de bemiddelaar aan de rechter dient te rapporteren over de inhoud van de bemiddeling. Meer dan de helft van de respondenten meent dat alle documenten die verband houden met het geschil maar die bestaan los van het bemiddelingstraject sowieso onder de vertrouwelijkheid van de bemiddeling vallen en dat deze dus niet meer gebruikt kunnen worden in een later rechtsgeding. Door het van kracht worden van de wet van 18 juni 2018 is een aantal van de bevindingen achterhaald. $\mathrm{Nu}$ bestaat de mogelijkheid dat de rechter de partijen een bemiddeling kan opleggen, tenzij alle partijen zich ertegen verzetten. Ook kunnen de partijen nu schriftelijk overeenkomen bepaalde documenten van buiten de bemiddeling onder de vertrouwelijkheid van de bemiddeling te brengen. ${ }^{25}$

- Broodroof: ${ }^{26}$ de perceptie dat bemiddeling een negatieve invloed heeft op de inkomsten van advocaten en een terugloop van het aantal zaken veroorzaakt (ADR als Alarming Drop in Revenu), heeft tot gevolg dat advocaten een negatieve houding aannemen tegenover bemiddeling. Bemiddeling kan inderdaad leiden tot een vermindering van het aantal aanrekenbare uren, maar dat kan worden ondervangen door het bedingen van een succes fee. ${ }^{27}$

- Onvoldoende betrokken: ${ }^{28}$ actieve betrokkenheid van de advocaat bij de bemiddeling kan leiden tot een sterk bemiddelingsakkoord. Dit lijkt onvoldoende doorgedrongen te zijn, op de eerste plaats bij de advocaten zelf. Sommigen menen ten onrechte dat bij bemiddeling voor hen geen rol is weggelegd en dat van hen een louter passieve aanwezigheid wordt verwacht. Ook zijn er bemiddelaars die menen dat advocaten best buiten de bemiddeling worden gehouden, omdat zij door hun agressieve houding het goede verloop van het

Ibid., p. 28-30.

Ibid., p. 30-32.

Het onderzoek werd uitgevoerd nog voor de nieuwe Bemiddelingswet in werking is getreden. Volgens de toenmalige regelgeving kon een rechter partijen geen gerechtelijke bemiddeling opleggen. Het onderzoek van Tom Wijnant wijst uit dat de advocatuur niet gevonden was voor het invoeren van collaboratieve onderhandelingen en gekant was tegen verplichte bemiddeling. Beide zaken werden echter wel ingevoerd door de wet van 18 juni 2018.

26 T. Wijnant, Bevraging van de Belgische advocatuur over bemiddeling: eerste resultaten, TMD 2018 (22) 1, p. 32-35.

27 Niet te verwarren met een in België verboden contingency fee - no cure no pay. Een succes fee geeft de advocaat boven op het basishonorarium een bonus als bepaalde overeengekomen doelstellingen worden bereikt. Ibid., p. 35. 
traject zouden storen. ${ }^{29}$ Dit alles duidt op een onvolkomen kennis van bemiddeling als instrument van conflictoplossing en illustreert de verdere noodzaak van doorgedreven opleiding van de professionele conflictoplossers.

\section{Wat kunnen Nederlandse en Belgische bemiddelaars van elkaar leren?}

Over de grenzen heen bestaat er consensus dat faciliterende bemiddeling de basishouding van de bemiddelaar is. De Belgische bemiddelaars passen daarbij sneller sturende technieken toe dan hun Nederlandse collega's, alhoewel het clienteel van laatstgenoemden graag meer sturing op het akkoord zou ondervinden. Het onderzoek maakt duidelijk dat bemiddelingspartijen graag een 'bemiddeling op maat' krijgen. Zij willen kunnen kiezen om een individueel intakegesprek te houden en om mediation proposals en bindende adviezen van hun bemiddelaars te ontvangen. Het zakelijke cliënteel blijkt sturende bemiddelaars op prijs te stellen, omdat dit de slaagkansen verhoogt. In België dient er rekening te worden gehouden met het effect dat zal voortvloeien uit de opname van de term neutraliteit in de Bemiddelingswet.

In Nederland is het enthousiasme van bedrijven om advocaten te betrekken bij een bemiddeling redelijk laag. Van advocaten wordt dikwijls ten onrechte gemeend dat zij een belemmering kunnen vormen voor het vinden van een minnelijke regeling. Het onderzoek van Tom Wijnant toont aan dat dit ook in België het geval is. In België zowel als in Nederland is er nog ruimte voor verbetering van de vaardigheden van advocaten om hun cliënteel in bemiddeling bij te staan. Daarbij kan worden gedacht aan de professionele voorbereiding van de bemiddeling met de cliënt, het ontwikkelen van communicatie- en onderhandelingsvaardigheden en het efficiënt bijstaan van de cliënt aan de bemiddelingstafel. Advocaten dienen met open vizier en met een bemiddelingsgerichte mindset aan de bemiddelingstafel te zitten. It takes two to tango, but everybody to perform a musical 